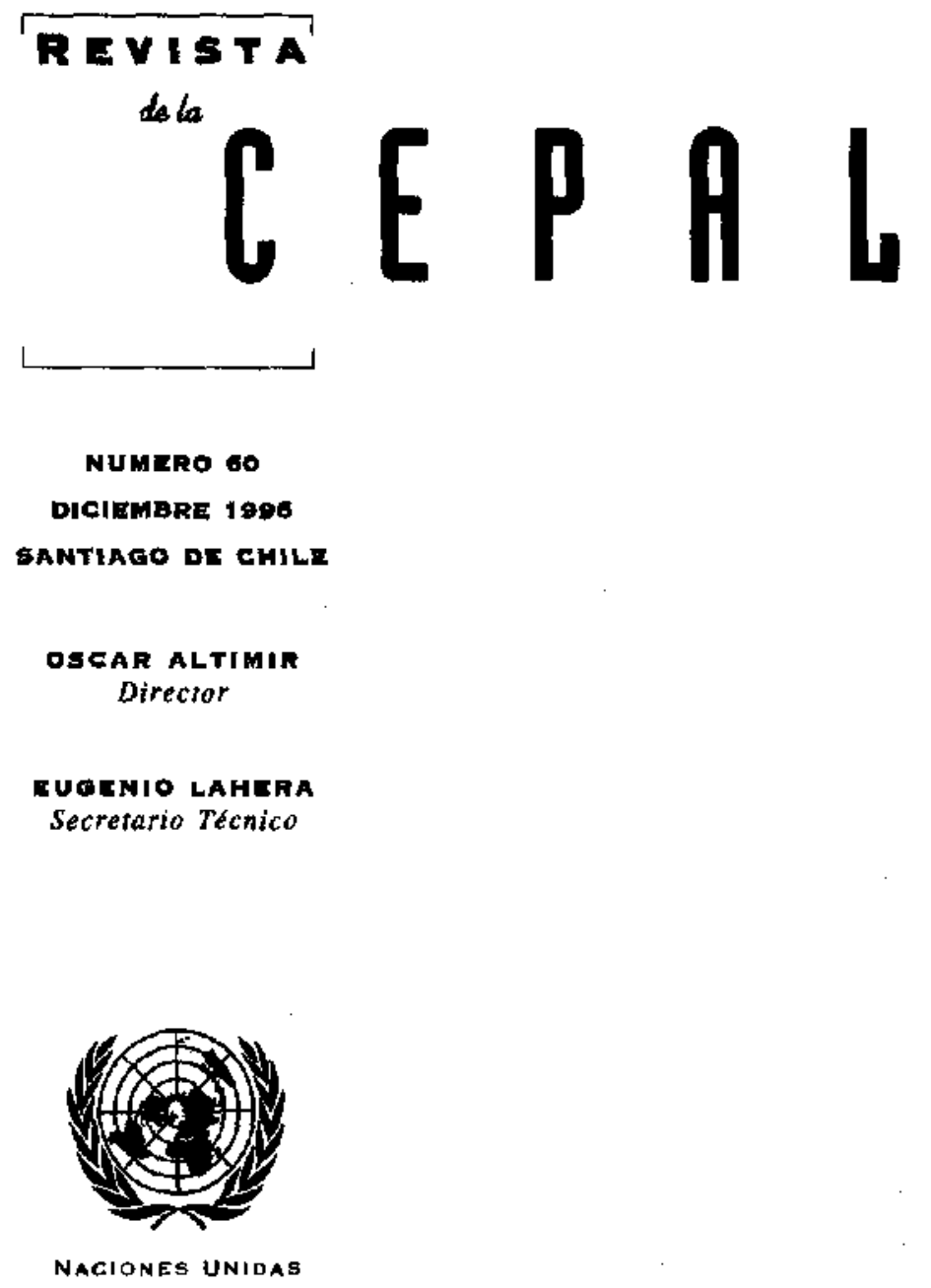


La evolución de las ideas y las políticas para el desarrollo

Gert Rosenthal

Políticas macroeconómicas para el crecimiento

Ricardo Ffrench-Davis

Flujos de capitales: lecciones a partir de la experiencia chilena

Eduardo Aninat, Christian Larrain

La transformación del desarrollo industrial de América Latina

José Miguel Benavente, Gustavo Crespi, Jorge Katz, Giovanni Stumpo

Las reformas de las pensiones en América Latina y la posición de los organismos internacionales

Carmelo Mesa-Lago

Aportes de la antropología aplicada al desarrollo campesino

John Durston

Prospección de la biodiversidad: potencialidades para los países en desarrollo

Julie M. Feinsilver

La inversión extranjera y el desarrollo competitivo en América Latina y el Caribe

Alejandro C. Vera-Vassallo

La crisis del peso mexicano

Stephany Griffith-Jones

Publicaciones recientes de la CEPAL 


\section{Prospección de la biodiversidad: potencialidades para los países en desarrollo}

\section{Julie M. Feinsilver}

Irvestigadora Superior, Consejo de Asuntos Hemișéricas Washington, D.C.

Acrualmente Especialista de Desarrollo Rural en

el $B D$, El Salvador
La biodiversidad, según algunos, es la nueva ventaja competitiva de los países en desarrollo: a ellos corresponde la soberanía sobre la mayor parte de la biodiversidad mundial, cuyo valor no se ha determinado aún. La prospección de la biodiversidad consiste en examinar recursos biologicos en busca de compuestos activos para uso farmacéutico, agrícola e industrial. En el presente artículo se describen cinco casos de prospección de la biodtversidad, se analizan sus perspectivas futuras y se examinan alternativas de politica para otras instituciones y paises interesados en practicar dicha prospección. El mercado de aceites esenciales (sobre todo para la fabricación de cosméticos), fitofármacos y preparados de hierbas, productos químicos agricolas y enzimas industriales es más amplio y accesible que el de compuestos nuevos potencialmente utilizables en la industria famacéutica. Dado el largo perfodo de prueba a que son sometidos los fármacos, es improbable que haya beneficios inmediatos; s1 existen posibilidades en el largo plazo. Además, se producen importantes efectos indirectos en atros sectores, en especial la agricultura y la industria, por cuanto se desarrolla capacidad científica para agregar valor en las distintas etapas del proceso de prospección de la biodiversidad y de elaboración de fármacos. Según las primeras conclusiones, la prospección de la biodiversidad puede beneficiar a los parses en desarrollo siempre que éstos tengan o creen condiciones adecuadas en cuanto a la infraestructura científica, las leyes de propiedad intelectual, las áreas de conservación y la capacidad de negociación, y cuenten además con voluntad política para colaborar entre sí y con las industrias de los países desarrollados. 


\section{I}

\section{Introducción}

La biodiversidad, según algunos, es la nueva ventaja competitiva de los parses en desarrollo: a ellos corresponde la soberanía sobre la mayor parte de la biodiversidad mundial, que la ciencia en buena medida aún no conoce y cuyo valor todavía no se ha determinado. La prospección de la biodiversidad, que consiste en examinar recursos biologicos en busca de compuestos activos para uso farmacéutico, agrícola e industrial, ha cautivado la imaginación de científicos, autoridades y ecologistas. Se ha dirigido principaimente hacia plantas medicinales y sustancias naturales con actividad biológica, por cuanto el "diseño racional de fármacos", mediante la bioquímica y las supercomputadoras, resultó más complejo de lo previsto. La prospección surge, entonces, como un modo de preservar la biodiversidad, dado el valor económico que podría tener en el proceso de descubrimiento de fármacos.

Hay también otras razones que han puesto en boga la prospección de la biodiversidad. Por ejemplo, más de $60 \%$ de la población del mundo depende directamente de las plantas para elaborar sus medicamentos: los chinos utilizan con fines medicinales más de 5000 de las 30000 especies de plantas que se calcula existen en ese país. Por su parte, la gran mayoría de los medicamentos occidentales deben su existencia a la investigación de los productos naturales de origen orgánico; de hecho, los productos naturales tuvieron intcidencia en la derivación de los 20 productos farmacéuticos más vendidos en los Estados Unidos en 1988 (Raven, 1994). Diez de los 25 de mayor venta en el Reino Unido en 1993 provenían también de fuentes naturales, ya sea por inspiración o por derivación (Ten Kate, 1995, p. 10). Al defender la biodiversidad -por su potencial futuro, o para investigarla mediante avanzadas técnicas cientuficas- suele decirse que menos de $10 \%$ de las 250000 especies floriferas (sin mencionar otras formas de biodiversidad) que se estima existen en el mundo han sido científicamente examinadas

ᄃ] El presente trabajo fue revisado y actualizado para la Revista de la CEPAL. El trabajo original, "Biodiversity Prospecting: Potential and Realities", fue presentado en el Taller que siguio al Congreso de la Sociedad de Genética de Malasia sobre perspectivas y problemas de la prospección de la biodiversidad, celebrado en Kuala Lumpur, Malasía, el 9 y 10 de noviembre de 1994. para detectar posibles propiedades medicinales, y que en el ańo 2050 probablemente una de cada cuatro de las plantas más evolucionadas se habrá extinguido antes de haberse explorado sus propiedades medicinales. ${ }^{1}$

Quizá lo más importante desđe la perspectiva farmacéutica sea lo señalado por el Dr. Gordon Cragg, jefe de la División de Productos Naturales del Instittto Nacional del Cáncer de los Estados Unidos: las complejas moléculas bioactivas que produce la naturaleza no pueden "inventarse", pero una vez descubierto su principio activo natural, se puede proceder a hacer modificaciones sintéticas para mejorarlo. ${ }^{2}$ La prospección de la biodiversidad es útil para seguir las pistas que da la naturaleza, pero es aún más importante para sugerir ideas sobre las cuales, con ayuda de la computación, se puede investigar estructuras químicas potencialmente de interés para la elaboración de fármacos.

Si bien las empresas farmacéuticas e instituciones de investigación siguen empleando computadoras para la fabricación de nuevos medicamentos, algunas de ellas han fomentado acuerdos con científicos de países en desarrollo para reunir e identificar especímenes de plantas, microorganismos e insectos, así como de flora y fauna marinas. Con muy pocas excepciones, el pars de origen proporciona muestras, las que se someten, en el exterior, a pruebas de detección de posible actividad biológica.

El primer acuerdo entre Merck, uno de los laboratorios más grandes del mundo, y el Instituto Nacional de Biodiversidad de Costa Rica (INBio), que contempla el pago de un milión de dólares al Instituto por concepto de servicios de prospección de la biodiversidad durante un período de dos años, ha suscitado polémicas y debates y ha creado tanto esperanzas como temores ante la perspectiva de repetir la experiencia en otros lugares del hemisferio occidental. Lamentablemente, la mayoría de las opiniones emitidas sobre el acuerdo por quienes no han participado directamente en él se basan en información incompleta, errónea o falsa.

\footnotetext{
${ }^{1}$ Akerele, citado en The Lancet, 1994, p. 1514

2 Citndo en Raven, 1994, p. 7.
} 
El presente trabajo describe en forma sucinta algunos casos de prospección de la biodiversidad en América Latina, en particular el acuerdo entre Merck y el INBio, y analiza sus perspectivas futuras. En la última sección se estudian posibles opciones para otras instituciones y países interesados en la prospección de la biodiversidad. La investigación se basa en un examen de gran parte de los estudios existentes (tanto publicados como inéditos) y en entrevistas y debates con personalidades significativas del sector; asimismo, aprovecha la experiencia adquirida por la autora al organizar el simposio interdisciplinario de la Organizacion Panamericana de la Salud (OPS) y el Instituto Interamericano de Cooperación para la Agricultura (IICA) sobre biodiversidad, biotecnología y desarrollo sustentable en la salud y la agricultura, y al cuidar la edición de sus resultados finales (Feinsilver, ed., 1996).

\section{II}

\section{Prospección de la biodiversidad:}

\section{experiencias y modelos}

La prospección de la biodiversidad ha existido desde tiempos inmemoriales, pero el término mismo es de reciente acuñación. Antes de darse a conocer el contrato entre Merck y el INBio en 1991, de celebrarse en Rio de Janeiro la Conferencia de las Naciones Unidas sobre el Medio Ambiente y el Desarrollo en 1992 y de publicarse Biodiversity Prospecting (del Instituto de los Recursos Mundiales y otros) en 1993, en la recolección de muestras de recursos biológicos participaban las instituciones y empresas de países desarrollados, ya sea directamente o mediante la adquisición de sus resultados. Desde la perspectiva de los países en desarrollo, gran parte de la responsabilidad correspondía a los principales jardines botánicos, que se entendian con las empresas productoras de fármacos y semillas agrícolas. Los beneficios obtenidos por la venta de productos elaborados a partir de estos recursos también quedaban en el exterior; de allí surgió el término "biopiratería".

Sin embargo, desde la Conferencia de Rio, muchos países han creado normativas sobre recolección y exportación de recursos biológicos, o han vuelto más estrictas las existentes, procurando con ello lograr mayor control y también captar parte de los beneficios económicos. La creación del Instituto Nacional de Biodiversidad de Costa Rica (INBio) marcó un hito en la prospección de la biodiversidad, por cuanto dicho Instituto canaliza directamente los beneficios de las actividades prospectivas hacia la conservación y pretende servir de modelo a otras entidades. Los breves estudios presentados a continuación dan una idea de los beneficios que los países de origen pueden obte- ner de diferentes tipos de arreglos para la prospeccion de la biodiversidad.

\section{Instituto Nacional de Biodiversidad de Costa Rlca (INBio)}

El INBio, establecido en 1989 por decreto oficial, se define como una institución de interés público, autonoma, privada y sin fines de lucro, que cuenta con el apoyo y la colaboración del Ministerio de Recursos Naturales, Energía y Minas (MIRENEM) para inventariar la biodiversidad de Costa Rica y buscar medios para conservarla y hacer sustentables su uso y desarrollo. Este arreglo institucional no gubernamental se concibió para promover la agilidad de operación y la flexibilidad y para facilitar la búsqueda de fuentes externas de financiación. La gran flexibilidad del Instituto le ha permitido aprovechar la financiación de fundaciones y organizaciones no gubernamentales (ONG), a la cual no habría tenido acceso si hubiera sido un organismo estatal.

Por otra parte, el carácter no gubernamental del INBio ha provocado cierta preocupacion, precisamente porque, sin estar bajo control estatal directo, maneja los sistemas de información sobre la biodiversidad del país y la recolección de especímenes. Podría pensarse entonces que "vende" dicha biodiversidad aunque de hecho no lo haga. Pese a la vocación de servicio de su actual direccion, se teme que el no rendir cuentas directamente al Estado no sea lo más conveniente para el país. Además, preocupa sobremanera el futuro, en caso de cambios en la dirección del Institu- 
to o de asunción al poder por parte del partido opositor, lo que crearía una relación distinta entre el INBio y gobierno. ${ }^{3}$ Por su parte, México, al crear una institución parecida al INBio con la asistencia directa de éste, optó por hacer de la conabio (Comisión $\mathrm{Na}$ cional para el Conocimiento y Uso de ta Biodiversidad) un organismo estatal encargado del inventario y la conservación, pero no todavía de la bioprospeccion. ${ }^{4}$

La prospección de la biodiversidad es la actividad más conocida y la división más visible del INBio. Sin embargo, es sólo una de las cuatro divisiones y actividades interrelacionadas del Instituto. Las otras tres son: i) el inventario de la biodiversidad, ii) el manejo de la información sobre ésta y iii) la divulgación de dicha información. El objeto de la prospección es encontrar usos novedosos y sustentables de la biodiversidad, a fin de conseguir parte de los recursos financieros necesarios para sostener las actividades de las demás divisiones, sobre todo el inventario, que sirve de base para toda la labor del INBio en pro de la conservación. ${ }^{5} \mathrm{El}$ análisis completo de todas las actividades del INBio supera los alcances del presente estudio y se puede encontrar en otros trabajos (Sittenfeld, 1993 y 1994; Aylward, Echeverría, Fendt y Barbier, 1993).

Las actividades de bioprospección del Instituto se basan en un amplio conocimiento de ciertos segmentos importantes de la biodiversidad de Costa Rica, que se encuentra en su inventario y en la capacidad cientifica del INBio y del país en disciplinas conexas. El INBio practica, en colaboración con industrias, instituciones de investigacion y universidades dentro y fuera del país, la prospección de la biodiversidad en busca de compuestos químicos, genes, especies, macro y microorganismos, mediante la recolección de especímenes, ya sea en forma aleatoria o con criterios quimotaxonómicos y ecológicos, así como la reunión de datos relativos a la ecoquímica, al comportamiento y a la historia natural. ${ }^{6}$ Asesora asimismo a otras instituciones en la esfera de la prospección de la biodiversidad. De hecho, uno de sus "productos" de más éxito es la idea de crear instituciones semejantes en

\footnotetext{
${ }^{3}$ Entrevistas a científicos de diversas instituciones de Costa Rica, agosto de 1993.

4 Véase el folleto informativo de la conabio.

${ }^{5}$ Entrevista a la Da. Ana Sittenfeld, Costa Rica, 24 de agosto de 1993.

- Ana Sittenfeld, informacion sobre el INBio para un cuadro de "Modelos de bioprospección" preparado por Julie M. Feinsilver a Ignacio H. Chapela para Feinsilver, 1996; conunicación personal, 24 de octubre de 1994.
}

otros parses; huelga decir que el INBio desempeña a la vez el papel de modelo y el de asesor y consultor externo (Juma, 1993, pp. 217 y 218; Chapela, 1996).

\section{a) El Acuerdo entre Merck y el INBio}

El singular acontecimiento que dio presencia mundial al INBio fue su contrato con Merck, algunos de cuyos detalles son de carácter reservado. Sí es del dominio público que en septiembre de 1991 Merck y el INBio firmaron un acuerdo en virtud del cual Merck pagaría por adelantado al Instituto un millón de dólares por identificar, reunir y extraer un número limitado de plantas e insectos, y por recolectar material que Merck utiliza para el cultivo de microorganismos (Caporale y Dermody, 1996, p. 16). Esta cantidad limitada de especímenes, cuyo número exacto se desconoce pero se estima en unos 2000 , se recogería en las áreas de conservación de Costa Rica en un período de dos años (Aylward, Echeverría, Fendt y Barbier, 1993, p. 49). A cambio de otorgar exclusividad en el acceso a tales muestras durante dos años, y de la posibilidad de examinarlas en relación con la salud y la agricultura, el INBio recibió asimismo más de 180000 dólares en equipos para los laboratorios químicos de la Universidad de Costa Rica participantes en esta empresa para el desarrollo de la propia capacidad de extracción del Instituto. Además, Merck se comprometí a capacitar, en sus propios laboratorios o en otros centros de investigación, a cuatro químicos y envió al país a dos especialistas de jerarquía para organizar a los científicos costarricenses y capacitarlos en tareas de dirección de laboratorios (Sittenfeld, 1993). Merck también se comprometió a informar al INBio acerca de toda actividad confirmada y reproducible observada en alguna muestra proveniente del Instituto. ${ }^{7}$

Las patentes de los inventos surgidos de esta colaboración serían propiedad de Merck, pero el INBio obtendrfa derechos sobre cualquier producto farmacéttico para uso humano o animal, o sobre cualquier compuesto químico de uso agrícola que inicialmente se aislara o se produjera a partir de una muestra suministrada por el INBio. La obligación de pagar derechos también se aplicaria a los productos derivados o análogos de tales compuestos. ${ }^{8}$ No ha sido revelado el

\footnotetext{
${ }^{7}$ Resumen de los términos del acuerdo de colaboración entre el INBio y Merck \& Co., Inc., folleto proporcionado por Pedro León, representante del INBio en la Mesa Redonda de Cuernavaca (México) de la Academia Internacional del Medio Ambiente, 6 a 8 de abril de 1994 , p. 2.

${ }^{8}$ lbid., p. 3 .
} 
monto de los derechos que percibiría el INBio en caso de elaborarse un producto basado en su colaboración con Merck; sin embargo, de acuerdo con las prácticas actuales de esta actividad, probablemente rondaría el $3 \%$ de las utilidades netas.

Sobre la base de unas 2000 muestras proporcionadas en dos años, Bruce Aylward y sus colegas estimaron que dichos derechos aicanzarían un valor actual cercano a los 350000 dólares, si se fabricara un fármaco; éste podría llegar incluso a uno y medio millones si se tratara de uno de los diez más vendidos en el mercado. Señalaron que la suma no es significativa, comparada con los beneficios obtenidos en capacitación, transferencia de tecnología y cobros por recoleccion de muestras (Aylward, Echeverría. Fendt y Barbier, 1993, p. 49). De una declaración formulada por Michael Dreyfuss, del laboratorio Sandoz, puede deducirse un dato más reciente acerca del valor de los derechos que el INBio percibiría, a una tasa del 3\%, en caso de producirse un fármaco. En efecto, el funcionario indicó que Sandoz (y cabría suponer que casi cualquier otro laboratorio transnacional) no invertiría en un compuesto cuyas ventas anuales bajaran de cien millones de dólares, por más eficaz que éste fuese: ${ }^{9}$ simplemente no les convendría, en ese caso, iniciar ningún proceso de elaboración. Si lo mismo sucediera en el caso de Merck, serfan aún menores las posibilidades de percibir derechos por parte del INBio.

En suma, mediante el acuerdo con Merck, INBio recibe un pago inicial por las muestras, $y$ asimismo transferencia de tecnologfa, desarrollo del capital humano y posiblemente derechos. A cambio, Merck obtiene acceso exclusivo a ciertas muestras del INBio, pero sólo para los fines señalados en el contrato y mientras dure la vigencia de éste. Esto no significa, sin embargo, que otra institucion, empresa privada o persona particular no pueda vender el mismo tipo de muestras a otra compañía, ni que el propio INBio esté impedido de vender las muestras de Merck a otra empresa, siempre que ésta no se dedique a la investigación en agricultura o en salud animal o humana. ${ }^{10}$ Hay una salvedad: Merck puede prorrogar el período de exclusividad para la evaluación de hasta $1 \%$ del total de las muestras proporcionadas, a condición de que actúe con diligencia en la evaluación y comercializa-

\footnotetext{
9 Entrevista a Ignacio H. Chapela, Washington, D.C., 9 de enero de 1995, en que se cita la presentación oral de Michael Dreyfuss. de Sandoz Pharma, Lid, en el Recurso Micológico de Oaxaca (Méxic), el 16 de diciembre de 1994.

10 lbid.
}

ción de éstas. " De ello se desprende que la expectativa de encontrar un compuesto novedoso es de $1 \%$ o menos. De hecho, el Dr. George Albers-Schonberg, científico de la plana mayor de Merck, dijo en 1991 que, de los compuestos de origen natural encontrados por Merck, Sharp y Dohme en los últimos 25 años, sólo cinco llegaron a ser, directamente o con alguna modificación química, drogas comercializables (Schweitzer y otros, 1991, p. 1295).

La cantidad de especímenes suministrados por el INBio es más bien reducida, sobre todo considerando que para funcionar con eficiencia los equipos de alta capacidad de la industria farmacéutica necesitan procesar un mínimo de 5000 muestras semanales, es decir, más del doble del aporte bienal del INBio. Lo dicho sugiere también que la contribución potencial del INBio al programa de descubrimiento farmacéutico de Merck es relativamente insignificante. Lo mismo puede decirse del costo para Merck: sólo 500000 dólares al año, de un presupuesto anual de 1200 millones para investigación. Los ingresos que recibe el INBio de Merck, por su parte, no son desdeñables, pero constituyen sólo una pequeña proporción de las demás fuentes de dotación y financiación con que éste cuenta, tales como subsidios de grandes fundaciones y, lo que es más importante aún, su acceso a 4600 millones de dolares procedentes de la reconversión de la deuda externa (intercambio de deuda por medidas de protección de los recursos naturales). ${ }^{12}$

Lo novedoso de este arreglo consiste en los pagos por adelantado, y en el compromiso del INBio de entregar el $10 \%$ del importe inicial (100 000 dólares) $y$ un 50\% de todos los derechos al Ministerio de Recursos Naturales, Energía y Minas, para mantener las áreas de conservación. Ya que el Instituto recoge sus muestras en dichas areas, es de su interés invertir en preservarlas y mantenerlas. Es importante también -aunque no exclusiva de este contrato-- la inclusión de la transferencia de tecnología y de la capacitación de científicos costarricenses.

¿Cuál es el valor del contrato para Merck? Según algunos, se limita a telaciones públicas. Gracias a él, Merck ha logrado mucha publicidad y ha sido calificada como empresa con conciencia ecológica (Chapela, 1996). Merck renovó en julio de 1994 su contrato con el INBio por dos afíos más, desplazando su interés principal hacia los insectos, aun cuando las plantas y

\footnotetext{
11 Resumen de los términos del acuerdo de colaboración entre el INbio y Merck \& Co., Inc., p. 2.

${ }^{2}$ Datos del INBio (1992), citados en Chapela, 1996).
} 
los microorganismos siguen tomándose en cuenta. Hasta enero de 1996, no había surgido de esta colaboración ningún indicio susceptible de llevar a la creación de nuevos fármacos. Del prìmer contrato emanaron s6lo dos publicaciones científicas: ambas eran artículos sobre hongos microscópicos en los desechos de hojas en el pafs, no trabajos sobre plantas e insectos, principales objetos del acuerdo (ibid). Curiosamente, el cultivo de microorganismos está a cargo de Merck y no del Instituto; este último no hace sino suministrar las materias primas para una de las contribuciones potencialmente más promisorias de la biodiversidad al proceso de descubrimiento de fármacos.

Caporale y Dermody (de Merck), aunque miran con buenos ojos la colaboración entre el INBio y su empresa, ponen de relieve la facilidad de la química combinatoria para generar diversidad molecular a una escala enorme: ésta puede sintetizar y examinar con rapidez miles o incluso millones de compuestos (Caporale y Dermody, 1996). Los laboratorios tienen gigantescos archivos químicos donde buscar moléculas que les den nuevas pistas. Los criterios de búsqueda y selección de ellas, sin embargo, cambian con gran celeridad, al ritmo de los progresos científicos y tecnológicos (Chapela, 1996). Aun así, y en conjunción con la química combinatoria, la biodiversidad sigue siendo útil para la industria farmacética. Por ejemplo, los productos naturales pueden proporcionar indicios de nuevas estructuras moleculares capaces de interactuar con el objetivo, dando as un marco inicial que puede optimizarse mediante la química combinatoria. Esta última requiere además fragmentos nuevos para incluir en la mezcla sintética, algunos de los cuales pueden ser difíciles o engorrosos de preparar en el laboratorio. Las enzimas nuevas, derivadas de microorganismos, facilitan el camino hacia tales fragmentos; éste es otro de los usos potenciales de la biodiversidad (Caporale y Dermody, 1996).

A modo de advertencia, cabe recordar que el Instituto Nacional del Cáncer de los Estados Unidos estima en general que de cada 10000 muestras de productos naturales sometidas a ensayo, solo una puede llegar al estadio siguiente (farmacología precínica). De cada diez que llegan a este estadio superior, una sola pasa a ser investigada con miras a transformarse en un nuevo fármaco. De cada diez sustancias en esta ûltima etapa, sólo una o dos llegan al mercado. En consecuencia, las probabilidades de que una determinada muestra lleve a un medicamento comercializable son de una en $250000 .^{13}$ Estas probabilidades podrían mejorar si las muestras se someten a varios tipos de pruebas. Por ejemplo, si la misma muestra se analiza en relación con cinco tipos distintos de líneas celulares, enzimas o modelos animales con un mecanismo bioquímico diferente para cada tipo de prueba, las probabilidades aumentan, no en forma lineal, pero seguramente a menos de una en $80000 .^{14}$ Por cierte, las cifras no son alentadoras; sin embargo la razon de ser del INBio no es la bioprospección, sino el inventario y la conservación de la biodiversidad. La bioprospección es un medio para alcanzar esos fines, y también ha obtenido considerable impacto publicitario para el Instituto.

\section{b) Perspectivas del INBio}

Las perspectivas para suscribir nuevos contratos con Merck y otras empresas de fármacos, productos químicos agrícolas y sistemas de gestión de la información sobre la biodiversidad son relativamente buenas para el INBio, por varias razones. En primer tugar, se ha comprobado su calidad y confiabilidad. Segundo, su fuerte programa de relaciones públicas, orientado a mejorar su situación financiera, le ha ganado el pleno apoyo de su gobierno, de buena parte de la comunidad ecologista internacional y de poderosos donantes.

Sin embargo, las mayores potencialidades de éxito comercial para el INBio no están en la bioprospección, sino en otras tres áreas. La primera es la promoción de instituciones semejantes en otras partes del mundo, con los consiguientes servicios de gestión de la información y asesoramiento; la segunda, el desarrolio de sistemas computacionales de información sobre biodiversidad, en asociación con la empresa estadounidense Intergraph; y la última, la elaboración de un nematiciđa natural descubierto por la empresa británica BTG para uso en la industria del banano. La primera posibilidad, es decir, la promoción del propio INBio como producto, comienza a concretarse, a medida que otros parses, instituciones, organizaciones no gubernamentales y organismos internacionales procuran obtener asesoramiento y ayuda, y que el INBio ofrece más servicios de consultoría. Con ello, tendrá considerable presencia en futuros adelantos vinculados a la biodiversidad, en las esferas del inventario, la conserva-

\footnotetext{
13 Entrevista al Dr. David Newinan, Instituto Nacional del Cáncer (NC) de los Estados Unidos, División de Productos Naturales, Frederick, Maryland, $1^{\circ}$ de noviembre de 1994.

14 Comunicación personal con el Dr. Gordon Cragg, Jefe de la División de Productos Naturales del Instituto Nacional del Cáncer (NC) de los Estados Unidos, 20 de enero de 1995.
} 
ción, la gestión y difusión de la información, así como de la prospección. Indudablemente, este hecho a su vez redundará en mayor financiamiento para el INBio.

La colaboración con la empresa Intergraph debería generar en el futuro cercano productos comercializables, sobre todo a medida que los países empiezan a elaborar el tipo de inventarios previstos en el Convenio sobre la Diversidad Biológica. Por último, el proyecto del nematicida plantea un desafío considerable, por cuanto el compuesto activo se encuentra en una planta en peligro de extinción. Si el INBio logra aislar este compuesto activo en las hojas en lugar de semillas (manteniendo la misma eficacia) y puede utilizar10 , obtendría sustanciales beneficios económicos, pues se trata de un nematicida biodegradable y no tóxico para los seres humanos. La inđustria del banano, altamente contaminante, se vería muy favorecida por este producto.

Respecto de la prospección de la biodiversidad, es difícil, sin acceder a los detalles del acuerdo, entender la argumentación científica o económica que avala el segundo contrato entre Merck y el INBio. Este nuevo contrato se centra principalmente, aunque no en forma exclusiva, en muestras provenientes de insectos, y no de plantas. Lynn Caporale, de Merck, opinó que brindaba a ambas partes la oportunidad de colaborar en una esfera de interés cientifico nuevo, sobre la que hay poco conocimiento. ${ }^{15} \mathrm{El}$ interés de Merck no parece justificarse fácilmente por razones de índole cientffica; es bastante difícil determinar la causa de un proceso en los insectos, ya que éste podría obedecer a innumerables factores independientes de la química del ejemplar, tales como cambios en su ubicación geográfíca, en sus patrones de alimentación u otros. No obstante, Caporale estima que los insectos son "un recurso de características únicas". ${ }^{16}$

Por otra parte, si el arreglo entre el INBio y Merck tiene tantas ventajas para la industria farmacéutica, cabe preguntarse por qué las demás companías importantes del ramo no siguen el ejemplo y entablan relaciones similares con instituciones en otros paises. Una posible explicación es que a casi todas las empresas farmacéuticas les interesa reservarse la libertad de elegir entre múltiples lugares geográficas y distintas instituciones y organismos de recolección que puecan proporcionarles muestras. Además, la mayoría preferiría no entregar dinero por adelantado en el marco de un contrato a largo plazo, y simplemente ir pagando

is Entrevista telefónica a Lynn Caporale, 23 de septiembre de 1994. 16 Ibid. por los especímenes a medida que los reciben. Por otra parte, la justificada rigidización de las normas de acceso a la biodiversidad del mundo en desarrollo puede llevar a las empresas farmacéuticas y de biotecnología a buscar en sus propios países las fuentes de suministro de muestras. Pfizer, por ejemplo, concertó un acuerdo con el Jardín Botánico de Nueva York para obtenerlas en los Estados Unidos, donde resulta más fácil.

Aunque el INBio no deba ni pueda reproducirse tal cual (Feinsilver y Chapela, 1996), cabe aprender mucho de su experiencia. Los interrogantes principales son los siguientes: ¿qué productos ha generado ya?, ¿cuáles están en elaboración?, ¿qué participaciôn en el mercado podrían tener sus productos futuros?, ¿es económicamente sustentable o sólo puede sobrevivir con subvenciones y asistencia técnica ad honorem?, ¿ha contribuido en realidad al desarrollo sustentable y, en caso afirmativo, ¿de qué manera?, ¿quiénes tienen intereses en el INBio y quiénes reciben sus beneficios?, ¿cuáles son los mecanismos de rendición de cuentas ante el Gobierno de Costa Rica?, zobtiene acaso la comunidad no cientffica algún beneficio economico con su labor? Por áltimo: ̨existe incompatibilidad entre los objetivos científicos de las políticas del INBio y la orientación de mercado de sus actividades de prospección de la biodiversidad, y, si así fuera cómo podría resolverse?

\section{Instituto Naclonal del Cáncer (NCI) de los Esta- dos Unidos}

La División de Productos Naturales del Instituto Nacional del Cáncer ( $\mathrm{NCl}$ ) de los Estados Unidos tiene una larga trayectoria en el ensayo de productos naturales para descubrir nuevas drogas contra el cáncer y actualmente también contra el síndrome de inmunodeficiencia adquirida (SIDA). En su carácter de organismo del gobierno federal, el NCI debe recurrir a empresas farmacéuticas para patentar y producir las drogas que descubre. En su primera etapa, de 1960 a 1982, analizó 114000 extractos de plantas, derivados de 35000 muestras, la mayoría de zonas templadas. En su segunda etapa, que se inició en 1986, el NCI trasladó su interés a plantas procedentes de zonas tropicales y subtropicales (Cragg y otros, 1994a, p. 178).

Desde 1986 el NCI ha suscrito contratos con tres instituciones estadounidenses para recolectar muestras de plantas de la región tropical y subtropical de África y en Madagascar, Centro y Sudamerrica y Asia sudoriental, y con otra institución para reunir muestras 
marinas. ${ }^{17}$ En todos los casos, se trata de entidades estadounidenses que tienen acuerdos de colaboración con organismos de los países de origen de las muestras. El NCI no trabaja directamente con ninguno de estos últimos, pero tiene otros acuerdos de colaboración con diez instituciones de países en desarrollo, principalmente para la investigación de sus plantas medicinales. ${ }^{18}$ El Dr. Cragg anticips que en agosto de 1996, cuando acabe la ronda actual de contratos quinquenales de recolección, el NCl eliminará a los intermediarios y adquirirá, cuando se pueda, muestras y extractos directamente a las instituciones de los países de origen. ${ }^{19}$

El éxito más notable del programa de investigación del $\mathrm{NCl}$ es sin duda el Taxol, decisivo avance en el tratamiento del cáncer ovárico y del cáncer mamario avanzado. Este fármaco se extrafa del tronco del tejo del Pacífico, pero actualmente se produce en forma semisintética (ambientalmente sustentable) a partir de las agujas y ramas del tejo del Himalaya (The New York Times, 1994). En este momento se encuentran en etapa de experimentación clínica otros tres compuestos anticancerosos derivados de plantas. En la primera etapa del programa fueron ocho los que pasaron a la fase de experimentación clínica, pero se desecharon debido a niveles inaceptables de toxicidad o a falta de eficacia (Cragg y otros, 1993a, p. 85). Si bien podría valer la pena volverlos a examinar con criterios más sofisticados, en opinion del Dr. Cragg es improbable que se haga; sería difícil que los médicos volvieran a considerartos, dado el altísimo nivel de toxicidad ya comprobado y, dada, además, la gran cantidad de nuevas perspectivas que se están explorando. ${ }^{20}$ Además de los resultantes del trabajo directo del NCI, hoy existen otros cuatro fármacos anticancerosos derivados de plantas, que, si bien no provienen de su programa de investigación, contaron con considerable asistencia del NCI para su desarrollo (Ibid, p. 81).

La política de recolección de muestras del $\mathrm{NCI}$ procura conseguir tanto plantas medicinales como colecciones taxonómicas más amplias (Cragg y otros, 1994a, p. 188). Curiosamente, ninguna de las tres drogas anticancerosas derivadas de plantas que han sido descubiertas por el (NCI) surgió de pistas etnobotánicas.

17 El Jardin Botánico de Missouri, el Jardín Botánico de Nueva York y la Universidad de llinois en Chicago, que colabota con el Amold Arboretum de la Universidad de Harvard y el Museo Bishop de Honolulu, Hawaii.

18 Programa de adquisición de productos naturales (impresión de computadora sin fecha) del Programa de Terapéulica Evolutiva, División de Tratamiento contra el Cáncer, NCL.

${ }^{19}$ Entrevista al Dr. Gordon Cragg, 28 de diciembre de 1994.

20. lbid.
En la lucha contra el virus de la inmunodeficiencia humana (VIH), hasta agosto de 1993 se habían sometido a prueba 21881 extractos derivados de más de 10500 muestras de 2320 plantas medicinales: $18 \%$ del total de las muestras y de las plantas dieron signos de alguna actividad. Al continuar con los exámenes, se comprobó que $90 \%$ de ésta se debía a polisacáridos o taninos comunes, que no se toman en cuenta en la elaboracionn de fármacos; por consiguiente, estas muestras quedaron al margen de las pruebas siguientes (Cragg y otros, 1994a, p. 178).

Es positivo que se hayan negociado o estén en proceso de negociarse acuerdos de licencias con Camerún, Nueva Zelandia y Sarawak (Malasia) para continuar la elaboración de fârmacos potencialmente útiles contra el vir, a partir de principios activos provenientes de muestras de plantas y de vida marina. MediChem ha patentado el Calanolide A, en acuerdo con Sarawak. La Michellamina B no se ha patentado aún, pero el NCI sigue cooperando a este respecto con Camerún. El Gobierno de Nueva Zelandia y varios grupos académicos neozelandeses continúan colaborando en los trabajos con el Halichondrin B, de origen marino. ${ }^{21}$

¿En qué beneficia a los países de origen su relación con el NCI? Primero, obtienen pago por sus muestras, de parte del contratista encargado de la recolección, mediante un acuerdo entre éste y el NCl. Segundo, reciben, a través del mismo contratista, los resultados de las pruebas realizadas con sus especímenes. Tercero, obtienen para su herbario nacional ejemplares certificados de las muestras. Cuarto, reciben financiamiento para la capacitación de grupos de cientfficos del país en materia de técnicas de aislamiento y ensayo. Quinto, pueden acceder a la metodología de líneas celulares y diagnóstico del cáncer y el viн. Sexto, tienen la primera opción para suministrar, en caso necesario, gran cantidad de materia prima para continuar las pruebas. Séptimo, tendrían participación en los derechos en caso de producirse un medicamento. En el contrato de recoleccion del NCI se especifica que los resultados positivos de las pruebas serán comunicados al país de origen, y que éste será compensado con una participación en las utilidaces de la droga resultante, por intermedio de la compañ́a farmacéutica concesionaria de la patente del gobierno federal (Cragg y otros, 1994b, pp. 13 y 14). En el gráfico 1 se presentan los beneficios para el país de origen en los distintos tipos de colaboración mencionados.

21 Entrevista al Dr. David Newinan, 29 de enero de 1995. 
GRAFICO 1

Benefliclos para el país de origen de las muestras en virtud de sus colaboraciones

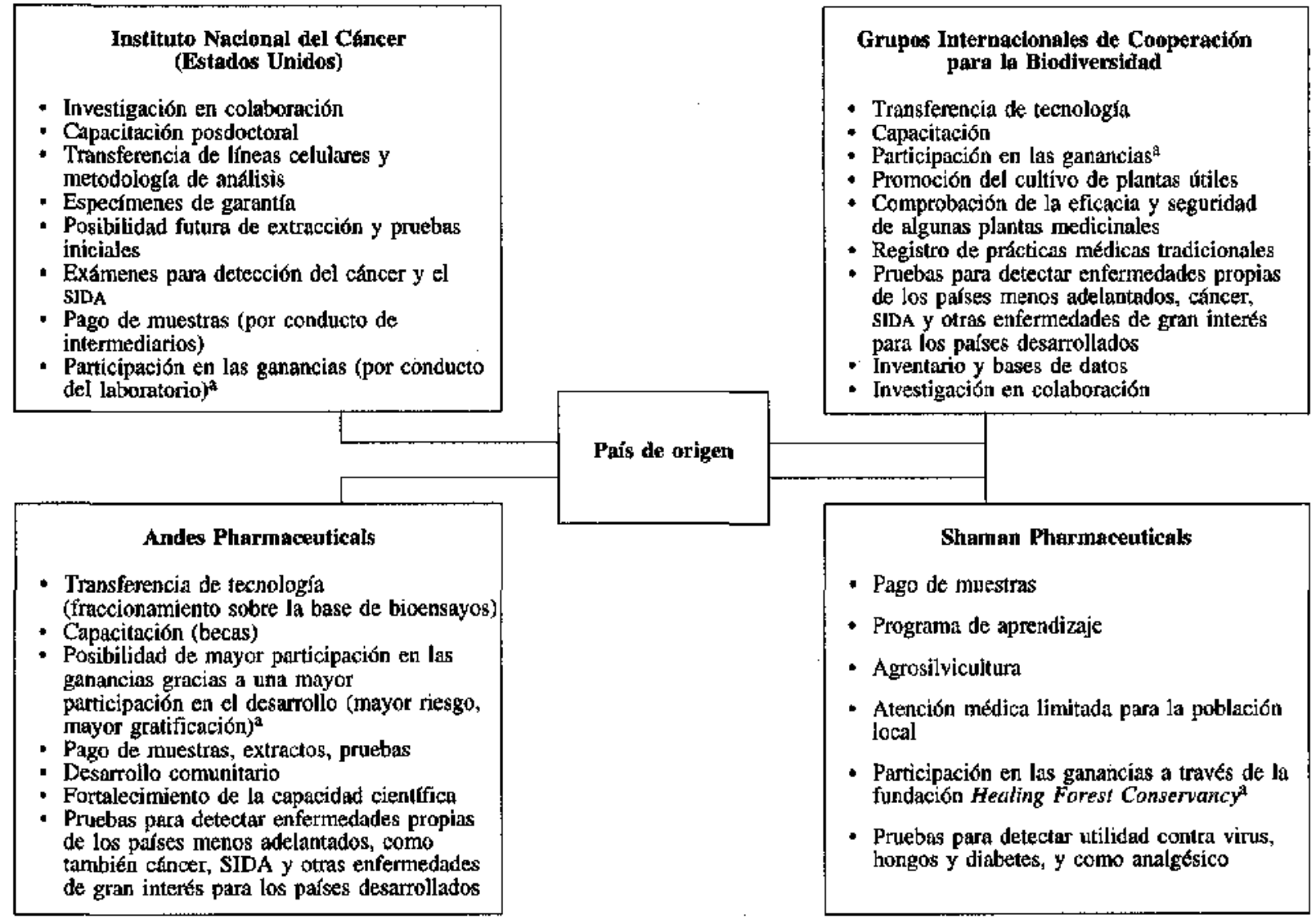

Fuente: Preparado por Julie M. Fejnsilver para Biodiversidad biotecnologia y desarrollo sosfenible en salud y agricultura: conexiones emergentes, editado por Julie M. Feinsilver (Washington, D.C. Organización Panamericana de la Salud, 1996).

a Participación en las ganancias siempre y cuando se produzca un fármaco.

Por último, el NCI contempla transferir en algún momento parte de los procesos de extracción y detección a instituciones calificadas de los parses de origen, probablemente después de agosto de 1996, al caducar los contratos de recolección vigentes y liberarse recursos para otro tipo de arreglos.22 Este cambio de polftica seguramente se debe al interés manifestado por los países de origen (desde la Conferencia de Rio en 1992) en controlar mejor el uso de sus recursos biologicos y en desarrollar su propia capacidad científica. Algunos han prohibido la participación de intermediarios en la

${ }^{22}$ Entrevista al Dr. Gordon Cragg, 28 de diciembre de 1994. recolección de muestras y, en su lugar, han establecido mecanismos propios para reunirlas y extraerlas; procuran además desarrollar su propia capacidad de detección.

Desde la perspectiva del Dr. Cragg, el descubrimiento de fármacos correspondería a los países de origen; en caso de haber un producto promisorio, el NCI prestaría su asistencia en la etapa de elaboración (desde estudios avanzados de toxicidad en animales hasta pruebas clínicas en seres humanos). La División de Productos Naturales del NCI se ha abocado a fomentar la capacidad de los países de origen, ayudándolos a crear sus propios servicios de extracción, aislamiento y detección, y colaborando con ellos en la elaboración 
de fármacos a partir de los compuestos activos que puedan descubrir ${ }^{23}$ Por otra parte, ningún pars lograría, aunque quisiera, alcanzar una escala de operación semejante a la del $\mathrm{NCr}$, ni cabría pretenderlo. En cambio, sí parece sensato buscar formas de colaboración de máximo beneficio económico y científico para el país de origen.

\section{a) Perspectivas del $\mathrm{NCI}$}

Dada sa vastísima colección de extractos de productos naturales, su gran número de líneas celulares de VIH y cáncer y su larga experiencia en el examen de productos naturales, el Ner tiene buenas perspectivas de descubrit o de facilitar el descubrimiento y la elaboración de fármacos anticancerosos y anti-yıH, lo que puede hacer en conjunto con las compaffías farmacéuticas o con los países de origen de las muestras. $\mathrm{La}$ forma en que se descubre una droga no es particularmente importante para el NCr, que está dispuesto a colaborar con quien sea en las etapas avanzadas de pruebas. ${ }^{24}$

Por otra parte, el NCI recibe unas 2000 muestras al añe de cada uno de sus tres contratistas, cifra pequeña para este tipo de actividad. Con algunas excepciones, no ha habido exitos, aunque sf indicios promisorios en etapas preparatorias; el acceso de sus resultados al mercado es aún problemático.

En el futuro proximo, los fondos destinados a la División de Productos Naturales del NCI pueden verse reducidos, por cuanto la nueva dirección se interesa más en la quimica combinatoria que en el descubrimiento de fármacos a partir de productos naturales. Además, dada la restricción presupuestaria, si el programa no produce compuestos nuevos para fines de siglo, puede ver amenazado su actual nivel de financiación.

\section{Grupos Internacionales de Cooperación para la Blodlversidad (ICBGs)}

Los Grupos Internacionales de Cooperación para la Biodiversidad son cinco consorcios de investigación para el desarrollo financiados por el Gobiemo de los Estados Unidos. Están abocados a un programa integrado, cuyos objetivos son la conservacion y el desarrollo, y que aborda temas interdependientes: la conservación de la biodiversidad, el crecimiento económico sostenido y la salud humana, en función de descubrir fármacos que ataquen enfermedades importantes

23 Ibid.

24 Entrevista al Dr, Gordon Cragg, 29 de diciembre de 1994. para los países en desarrollo y los desarrollados (Grifo, 1996). En los cinco consorcios, financiados por el Instituto Nacional de la Salud, la Fundación Nacional para la Ciencia y la Agencia de los Estados Unidos para el Desarrollo Internacional (USAID), participan universidades y laboratorios estadounidenses, instituciones de investigación de los países de origen, comunidades locales y organizaciones no gubernamentales. Tres de los consorcios funcionan en un solo pais: uno en Costa Rica, uno en Perú y otro en Suriname; los dos restantes, en varios parses: uno en Argentina, Chile y México, y otro en Camerún y Nigeria. Cada uno de los consorcios ha obtenido por concurso subvenciones de entre 400000 y 475000 dolares anuales durante cinco años, a partir de 1994, para cumplir con su objetivo de promover la conservación y el desarrollo sustentable mediante la búsqueda de nuevos fármacos derivados de productos naturales. Registrarán, además, las prácticas de la medicina tradicional, brindarán capacitación y transferencia de tecnología, prepararán inventarios de biodiversidad para proyectos específicos, elaborarán métodos para extraer de manera sustentable el material de donde podrían derivarse fármacos de interés económico y suministrarán fondos para la conservación (Grifo, 1996; USAJD/NIH/NSF, 1993, pp. 1 y 2).

Esta labor interinstitucional comenzó a desarro1larse en 1991. Sin embargo las subvenciones son recientes, y por ello hay poca información sobre sus avances. En un informe preliminar se indica que, de las 2000 especies de plantas e insectos analizadas, 120 registraron actividad biológica; no se sabe aún cuántas ya son conocidas, por lo que se hacen estudios para evitar duplicaciones. De éstas se han escogido 25 para examinar su utilidad en el tratamiento del cáncer, los trastornos del sistema nervioso central, la malaria y las enfermedades virales. Se han capacitado alrededor de 75 estudiantes y técnicos de Estados Unidos y los países en desarrollo, y se han producido importantes avances en la infraestructura de las instituciones de por lo menos seis países de origen. ${ }^{25}$

Para estos últimos, los beneficios de este tipo de colaboración son considerables: transferencia de tecnología, capacitación importante en distintas áreas, asistencia en la esfera del desarrollo sustentable, fortalecimiento de la capacidad, sistemas de información sobre la conservación, preservación de los conocimien-

25 Joshua Rosenthal, cornunicación personal del 31 de enero de 1996, sobre la base de Rosenthal, (por publicarse). 
tos autóctonos y, por último (sin restarle importancia), justa compensación en caso de fabricarse un fármaco a partir de las muestras que suministren. Lo principal, sin embargo, es la colaboración de los países de origen en el comienzo mismo de los proyectos, y su plena participación en el điseño y la ejecución de éstos. Por desgracia, estas ventajas están al alcance de muy pocos países, dadas las limitaciones del financiamiento.

\section{a) Perspectivas de los Grupos}

Si no se produce un descubrimiento farmacológico trascendente en los próximos cuatro años, Jas perspectivas de futura financiación de los Grupos no son muy alentadoras. No es muy probable ese tipo de descubrimiento, por cuanto las pruebas, el desarrollo de productos y la aprobación de la Dirección de alimentación y fármacos (FDA) de los Estados Unidos suelen demorar decenios, pese a buenas intenciones y esfuerzos. Ante un Congreso con predominio republicano y una meta de equilibrio en el presupuesto federal en un plazo de siete años, lo más probable es, en realidad, que las prioridades presupuestarias se asignen a otras actividades. Los fondos disponibles para el ejercicio económico 1996 ya han sufrido un recorte respecto del año anterior, dado que la uSAID ha reducido de 500000 a 150000 dólares su contribución a los Grupos. Es más, en los ejercicios económicos 1997 y 1998 dicha Agencia no contempla proporcionarles financiación alguna. ${ }^{26}$ Por otra parte, la dirección de los Institutos Nacionales de Salud tiene previsto reevaluar todos los programas internacionales, lo que también podría llevar a una reducción de los fondos.

Aun así, será valiosa la experiencia adquirida al establecer estos consorcios cientificos de colaboración Norte-Sur, así como la transferencia de tecnología y la capacitación que implican, aunque difícilmente puedan repetirse sin importante financiación externa. Es muy improbable que la industria farmacéutica invierta por su parte suficientes recursos como para mantener a flote el proyecto, dado que, según algunos críticos, los Grupos son en realidad un subsidio federal para las actividades de investigación farmacéutica de los laboratorios estadounidenses. Para apreciar este carácter de subsidio, baste decir que, hasta enero de 1996, las compañias farmacéuticas integrantes de los cinco consorcios aportaron inversiones destinadas a ensayos nacionales por un valor apenas superior a los 300000 dólares, y algo más de 150000 dólares en pagos adelantados, infraestructura y actividades de fortalecimiento de la capacidad de los parses de origen de las muestras. ${ }^{27}$ Este aporte equivale a unos 45000 dólares al año por consorcio, suma insignificante comparada con los más de 1000 millones de dólares al año que las compañías dedican a las actividades de investigación para el desarrollo. Así, dadas las escasas perspectivas de contar con financiación del sector privado, y dado el interés del Congreso y de los organismos públicos en buscar maneras de recortar aún más el presupuesto, no parece muy auspicioso el futuro de los Grupos Internacionales de Cooperación para la Biodiversidad.

\section{Shaman Pharmaceuticals, Inc.}

Shaman Pharmaceuticals es una empresa farmacéutica de productos naturales, pequeña y relativamente nueva, todavía sin productos en el mercado. Busca compuestos activos mediante métodos de recolección etnobotánicos. Si tres o más culturas diferentes utilizan de manera similar una determinada planta, ésta se envía a los laboratorios de Shaman en California para aislar su principio activo y ver su utilidad contra males, como los virus, los hongos o la diabetes, y su eficacia como analgésico (Zisson, 1993, p. 2). Shaman estima que acierta en un $50 \%$ de los casos; pero su definición de acierto es muy imprecisa, y no hay datos fehacientes que corroboren su afirmación. No obstante, a sólo dos años de iniciar sus actividades, la empresa logró llevar dos compuestos a la etapa de pruebas clínicas. Este resultado notable no equivale necesariamente, sin embargo, a dos productos comercializables.

El prìncipal compuesto de Shaman es el Provir (SP303). Se trata de un antivirósico derivado de la sangre de drago, tátex rojo del Croton lechleri, especie muy difundida y comúnmente utilizada en Sudamérica contra las enfermedades gastrointestinales y respiratorias, y también como curalotodo. El Provir alcanzó la segunda fase de pruebas clínicas para determinar su utilidad contra el virus sincitial respiratorio, pero no demotró suficiente actividad. Volverá a la misma fase de pruebas pero esta vez como posible antidiarreico (BioVenture View, 1995b). El Virend es una versión del SP303 para uso externo en el tratamiento del virus del herpes simplex oral y genital. Puesto 
que el mercađo está bien cubierto por el Zovirax, Shaman apunta a otro mercado: el de personas resistentes a dicha droga (Zisson, 1993, p. 6). El éxito obtenido en la segunda fase de las pruebas en pacientes con SIDA llevó a Shaman a diseñar una tercera, con miras a que la FDA (Dirección de alimentación y fármacos de los Estados Unidos) la apruebe en forma rápida para su venta sin receta médica. A la vez, busca socios europeos y japoneses para elaborar y comercializar el Virend en el extranjero (Pharmaceutical Business News, 1995). Las buenas noticias sobre las pruebas clínicas hicieron subir las acciones de Shaman a 7 dólares, lo que equivale a un aumento de $14 \%$ (The Wall Street Journal, 1995, B11, p. 6).

El otro compuesto importante de este laboratorio, el \$P1100, es una familia de antimicóticos con un mecanismo de acción supuestamente muy novedoso, sin relación aparente con los azoles y polienos de la actual terapia; se prevefa iniciar la primera fase de pruebas en 1995 utilizando análogos, por cuanto la fórmula original era de muy baja biodisponibilidad y acarreaba cierta toxicidad sistémica (Zisson, 1993, pp. 8 y 9). A mediados de noviembre de 1994 , sin embargo, la empresa anunció que no proseguiría estas tareas, dado que exigían un gran esfuerzo médico y químico que no coincidía con las fortalezas de la compañía (The Bernstein Report on BioBusiness, 1994, p. B1). En cambio, intentaría patentar el compuesto para seguir trabajando en él y buscaría socios para llevar el Provir y el Virend a la tercera fase de las pruebas clinicas (ibid.).

Desde la reestructuración de mediados de noviembre de 1994, Shaman cambió su orientación: de la recolección etnobotánica pasó a los ensayos con modelos de animales vivos. Esto último contradice la práctica aceptada, que consiste en hacer primero pruebas in vitro y luego en vivo; la compañía sostiene que su procedimiento ahorra tiempo y por ende dinero. $\mathrm{Se}$ dedicará preferentemente a aquellas áreas en que convenga más este tipo de pruebas. Por consiguiente, bajó el perfil del programa antiinfeccioso, eliminando pruebas con antimicóticos y recortando las de antivirósicos; investigará en cambio la diabetes, los trastornos del sistema nervioso central, las enfermedades inflamatorias y síntomas tales como problemas respiratorios y gastrointestinales de origen infeccioso, temas todos de mayor interés para la industria farmacéutica, de quien busca conseguir financiación (Ibid.).

A diferencia de los modelos de bioprospección anteriores, Shaman es una empresa con fines de lucro y por lo tanto se financia mediante capital de riesgo, ingresos provenientes de la concesion de licencias, acciones que se cotizan en el sistema NASDAQ y fondos de empresas asociadas. Se debe finalmente a las utilidades, pero pretende ser mucho más cuidadosa que otras empresas en su trato con las comunidades locales y los pueblos indígenas (Chapela, 1996). Shaman Pharmaceuticals obtiene información de curanderos tradicionales del mundo en desarrollo, y a cambio promete retribuirla en caso de elaborar fármacos a partir de ella; presta cierta atención médica a las comunidades participantes, y suministra bienes y servicios diversos, que éstas hayan señalado como necesarios. Por ejemplo, en una reunión celebrada recientemente, el $\mathrm{Sr}$. Steven King, vicepresidente de Shaman, dijo haber suministrado tubos de pyc a una comunidad que los había solicitado. Si bien recibió fuertes críticas por el canje de tubos por conocimientos autoctonos, ${ }^{28}$ la entrega de los tubos tenía por objeto crear confianza y mejorar las relaciones con la comunidad, no sustituir la retribución debida en caso de elaborarse un producto.

En una reciente solicitud de patente presentada por Shaman, no se menciono comunidad indigena alguna, aunque la información correspondiente a la elaboración del producto era etnobotánica (Ibid.). Ante las críticas, King manifest 6 que la solicitud indicaba que la planta se consideraba ampliamente conocida, que se utilizaba en toda América del Sur, y que la compañía no podfa circunscribir su origen a una comunidad en particular. ${ }^{29}$ Una de las funciones de la Healing Forest Conservancy, fundacion creada por Shaman Pharmaceuticals, es establecer mecanismos para que las distintas comunidades participantes en el proceso de descubrimiento de fármacos puedan compartir los beneficios. En ausencia de estos últimos, no se ha planteado aún qué comunidades tendrían esa facultad; todas las que participan del mismo conocimiento, aunque Shaman no se los haya solicitado, podrían impugnar los "derechos" de aquellas seleccionadas por la empresa para suministrar información. Puesto que la legislación estadounidense sobre el tema no autoriza la inclusión de pueblos o comunidades indígenas en las

\footnotetext{
${ }^{28}$ Observaciones formuladas en la Reunión de seguimiento del Simposio sobre Biodiversidad auspiciada por la Organización Panamericana de la Salud (ops) y el Instituto Interamericano de Cooperación para la Agricultura (IICA), Washington, D.C., 22 de octubre de 1994.

29 Entrevista al Dr. Steven King. vicepresidente de etnobotánica y conservación, Shaman Pharmaceuticals, Inc., en Cuernavaca, México, 8 de abril de 1994.
} 
patentes, éstos carecen de protección legal a menos que suscriban además un acuerdo (contrato) separado con Shaman, para obtener parte de las utilidades futuras.

Dado que tiene fines de lucro, Shaman no imparte capacitación a los científicos de los países de origen; tampoco presta ayuda en materia de fortalecimiento de la capacidad cientffica ni de transferencia de tecnología. Exhibe una mayor sensibilidad cultural que otras compañ Łas similares, por cuanto su existencia y su éxito dependen de mantener buenas relaciones con los curanderos indígenas que pueden proporcionarle la información etnobotánica que necesita. Así pues, no es casualidad que haya creado un programa Shaman de formación de aprendices (concepto adoptado luego por algunos de los Grupos Internacionales de Cooperación para la Biodiversidad, siguiendo su ejemplo) y la Healing Forest Conservancy; ambos para preservar y promover la medicina tradicional.

Se le ha criticado una capacidad para recaudar fondos que no obedece al desarrollo de productos posibles, sino más bien a la extraordinaria publicidad que dan los medios de información a la pérdida de la biodiversidad y a las instituciones que aparentemente contrarrestan dicha percida (Ibid.). Hasta septiembre de 1993, el déficit de Shaman era de 22.2 millones de dolares, con una pérdida operativa de 13.3 millones de dolares hasta mayo de $1993 .{ }^{30}$ Luego se embarcó en un gasto de 500000 dólares a cuenta de ingresos correspondientes al cuarto trimestre de 1994, para sufragar la reestructuración (The Bernstein Report on BioBusiness, 1994, p. B1). Sin embargo, esta práctica es habitual en la industria de la biotecnología, con la cual Shaman parece tener más en común que con la farmacéutica. ${ }^{31}$

La reestructuración de la empresa tiene por objeto reducir los gastos de operación, lograr un mejor perfil en el mundo de las compañáas de investigación farmacéutica biotecnológica que buscan formar alianzas estratégicas con gigantes farmacéuticos, y, en general, hacerla viable. Según informa la companfía, ésta seguirá dedicándose a los productos naturales y mantendrá su criterio etnobiológico frente a la recolección, as! como la Healing Forest Conservancy. ${ }^{32}$

\footnotetext{
${ }^{30}$ En Chapela (1996), se cita un "Financial Fact Sheet" de 1994 de Shaman Pharmaceuticals.

${ }^{31}$ Sobre las coincidencias con la industria de la biotecnologfa véase Chapela (1996), y sobre las pérdidas de dicha industria, Burril y Lee Jr.. 1993, p. VII.

${ }_{32}$ Comunicación personal con Martha, ayudante de Steven King 3 de enero de 1995 .
}

\section{a) Perspectivas de Shaman}

Las perspectivas de la empresa dependen en gran medida del buen resultado de sus principales compuestos, y de su capacidad para seguir recaudando capital suficiente $y$ formando alianzas estratégicas a fin de continuar probándolos y desarrollándolos. En la reciente decisión de Eli Lilly de no renovar su contrato con Shaman puede verse una pérdida de confianza en la companía o en su enfoque etnobotánico sobre la investigación de drogas (The Wall Street Journal, 1994, B7, p. 1). En cambio, Shaman acaba de formar una nueva saciedad con Ono Pharmaceuticals de Japón, en virtud de la cual esta última aporta capital de investigación y Shaman nuevos compuestos activos, en un proyecto para elaborar un agente hipoglicémico oral para tratar la diabetes. Si el proyecto logra su objetivo, los derechos exclusivos de fabricación y comercializacion en Japón, la República de Corea y la provincia china de Taiwán corresponderán a Ono (Biotechnology Newswatch, 1995). Alejándose de la etnobotánica, Shaman ha adquirido bajo licencia de Bayer algunas patentes y datos preclínicos, con miras a producir agentes antimicóticos. En caso de elaborarse un producto eficaz, Shaman pagará derechos a Bayer (Bioventure View, 1995a).

Las ventas del Aciclovir, el único tratamiento para el herpes genital aprobado por la FDA (Dírección de alimentación y fármacos de los Estados Unidos), superaron los 1400 millones de dólares en 1994 ( $A I D S$ Weekly, 1995). Aś́, si el Virend pasa con exito la tercera fase de pruebas y resulta comercialmente viable en términos de costos de producción, Shaman podría recuperar sus pérdidas, atraer nuevas inversiones y alianzas estratégicas, y producir utilidades.

\section{Andes Pharmaceuticels, Inc.}

Andes Pharmaceuticals es una compañía dedicada a la investigación de productos naturales con fines farmacéuticos. Su objetivo es la prospección responsable de la biodiversidad mediante la creación de empresas conjuntas en los países de origen; para hacerlo, les transfiere apoyo, conocimientos y su propia tecnología de investigación de productos naturales. ${ }^{33}$ Gracias a este arreglo, los parses pueden agregar mayor valor a su biodiversidad, controlar mejor su uso y la elaboracion de productos y desarrollar su propia capacidad

33 Entrevista a Edgar Asebey, presidente de Andes Pharmaceuticals, Washington, D.C., $1^{\circ}$ de febrero de 1996. 
cientifica. Andes establece alianzas estratégicas con universidades, instituciones y organizaciones no gubernamentales del país de origen, así como con el sector privado de éste.

En Colombia, por ejemplo, tiene arreglos de colaboración con dos universidades y dos organizaciones no gubernamentales; acaba además de formar su primera empresa conjunta, BioAndes de Colombia, S.A., con un socio colombiano. Estos socios dentro del país, entre ellos las universidades y las organizaciones no gubernamentales, participarán de la propiedad de la empresa conjunta; el país, en consecuencia, no será solo una fuente de mano de obra barata. Al asumir mayores riesgos se logra una mayor transferencia de tecnología y mayor participacion en las eventuales ganancias por comercialización de fármacos, en caso de descubrirse y elaborarse alguno. ${ }^{34}$ Aunque las actividades de investigación farmacéutica se realizarán en laboratorios de propiedad de BioAndes, la compañía utilizará la capacidad científica existente y contribuirá a ampliarla mediante la colaboración con universidades e institutos de los países de origen. ${ }^{35}$ Los primeros resultados de los ensayos biologicos del proyecto piloto de BioAndes se esperan para fines de 1996.

Las metas declaradas de Andes Pharmaceuticals son: la transferencia de tecnología a países en desarrollo; la conservación mediante la actividad económica sustentable; el fortalecimiento de la capacidad de los países en desarrollo; una retribución justa para las comunidades locales e indígenas y la creación de oportunidades para que las entidades y colaboradores de los países de origen participen en las ganancias. ${ }^{36}$ Sus actividades concretas comprenden la recolección de plantas con criterios etnobotánicos y taxonómicos, y la recolección aleatoria de plantas, microbios del suelo y hongos, depositando especímenes de garantía en los paises de origen y los herbarios internacionales; el análisis y fraccionamiento, sobre la base de ensayos biologices, en los laboratorios de investigación de la empresa conjunta, ubicados en el país de origen; la transferencia de tecnología (equipos, conocimientos y otros) a las contrapartes correspondientes del pats de origen (es decir, universidades, instituciones, etc.); el

\footnotetext{
34 Asebey, 1996, y entrevista a Eojgar Asebey, 30 de diciembre de 1994.

${ }_{35}$ Entrevista a Edgar Asebey, Washington, D.C., 6 de enero de 1995.

${ }^{36}$ Edgar Asebey, información para madelos de bioprospección, destinada a Biodiversidad, biotecnología y desarrollo sostenible en salud y agricultura: conexiones emergentes (Feinsilver, ed., 1996).
}

fortalecimiento de la capacidad a través de adecuadas relaciones de colaboración y asociación en el país de origen; la capacitación técnica de los habitantes del lugar cono guías y parataxónomos, y de los científicos y estudiantes del pars (universitarios y superiores) en áreas relacionadas con la prospección de la biodiversidad, y la difusión de información en el pars de origen, para promover tanto la medicina tradicional como las publicaciones científicas orientadas a la comunidad internacional. ${ }^{37}$

Otras compañías, como Shaman Pharmaceuticals, envían las muestras a los Estados Unidos para su análisis, pero Andes Pharmaceuticals, en cambio, contrata personal en el país de origen para hacerlo. Este procedimiento no sólo ofrece grandes oportunidades de transferir biotecnología a los países en desarrollo y fortalecer su capacidad cientffica, sino que permite que los países de origen agreguen mayor valor a su biodiversidad. Además, algunos ensayos biológicos se realizan en el terreno mismo, con equipos portátiles simplificados producidos por Andes especialmente con este fin. En estos ensayos se utilizan muestras frescas en lugar de secas, lo que debería traducirse en una mayor actividad (Asebey, 1996). A mayor valor agregado a escala local, mayor la proporción de beneficios que obtiene el país de origen. En consecuencia, el enfogue propuesto por esta empresa puede crear una motivación económica para la conservación de la biodiversidad.

\section{a) Perspectivas de Andes Pharmaceuticals}

En el corto plazo, la empresa tiene buenas perspectivas de conseguir considerable financiación y de acceder a los recursos de los países de origen: se ha ganado el apoyo de inversionistas e instituciones cientfficas de América Latina, Europa y Estados Unidos. Por demostrar una firme dedicación a la transferencia de tecnología y a la conservación en los parses de origen, también cuenta con el apoyo de grandes organizaciones ecológicas internacionales tanto de América Latina como de Estados Unidos. Con ello se reafirma la legitimidad de sus actividades y se facilita la recaudación de fondos.

También son buenas sus perspectivas en la investigación de fármacos, por cuanto los ensayos que realiza están expresamente diseñados para productos naturales, y resultan entonces más eficientes que los usados para fines generales. El Consejo Consultivo de

31 bid 
Andes está integrado por un formidable grupo de científicos, algunos de los cuales pertenecieron al $\mathrm{NCI}$ de los Estados Unidos. De hecho, el principal responsable científico de Andes en la actualidad fue quien disef̂́ en dicho Instituto las pruebas para posibles agentes anticancerosos. ${ }^{38}$ Las actividades de investigación farmacéutica de la empresa se desarrollan en el pais de origen, donde accede en forma confiable a parte de la biodiversidad más rica del mundo y ptuede analizarla en forma sistemática. Por último, Andes negocia en la actualidad alianzas estratégicas con varias de las compañías de biotecnología estadounidenses que han aceptado los principios del Convenio sobre la Diversidad Biologica a fin de garantizar el acceso a los recursos genéticos.

La realidad que enfrenta esta empresa, al igual que las demás, es que la búsqueda de nuevos fármacos es un proceso largo y arduo, con riesgos extremadamente altos y escasas probabilidades de éxito. Sin embargo, puede ser que la favorezca su afán de descubrir drogas de utilidad para los países en desarrollo, sobre todo para el país de origen, y no sólo las que atacan enfermedades importantes para los países desarrollar dos.

\section{III}

\section{Opciones de política para otras}

\section{instituciones y países}

En general, cuando las autoridades analizan las perspectivas de la prospección de la biodiversidad, mencionan el acuerdo entre el INBio y Merck como ejemplo del potencial de beneficios que ésta ofrece. No se dan cuenta, sin embargo, de que quizá no sea esa la mejor manera de lograr sus metas, ni desde el punto de vista de la eficiencia ni de la eficacia en función de los costos. Sin embargo, la prospección de la biodiversidad efectivamente estimula el desarrollo de la capacidad científica en distintas areas, y este esfuerzo científico y educacional repercute favorablemente en otros sectores económicos.

La prospección de la biodiversidad sólo beneficia a los países en desarrollo si éstos reciben tecnología y capacitación suficientes para aumentar su propio potencial biotecnológico, condición necesaria dado el creciente desfase científico y tecnológico entre los países. Sin una mínima comprensión de la biotecnología, será difícil decidir cuáles son las necesidades tecnológicas del país y qué políticas ambientales, científicas y de desarrollo económico deben formularse, lo que llevará a una marginalización económica aún mayor. ${ }^{39}$

\footnotetext{
38 Entrevista al Dr. David Newman, 29 de enero de 1996.

39. Se podrfa afirmar que Cuba, que atraviesa enormes apuros económicos, habria estado mucho peor en el campo de Ja agricultura, la industria y la medicina si el gobierno revolucionario no hubiera hecho fuertes inversiones en materia de ciencia en general y
}

La prospección de la biodiversidad también es útil en combinación con otros intentos de producir remedios científicamente convalidados y normalizados a partir de hierbas con miras a atender necesidades de atención primaria de salud en el mundo en desarrollo y en algunos países europeos, donde son comunes los fitofármacos y los remedios de ese origen. Un editorial aparecido hace dos años en The Lancet (18 de junio de 1994) considera urgente el análisis de plantas en busca de posibles beneficios terapéuticos; afirma además que se debe dar prioridad a las enfermedades tropicales crónicas e infecciosas, cuyo actual tratamiento medicamentoso presenta serios inconvenientes, y a la evaluación científica de algunos remedios a base de plantas que, para la automedicación, podrían ser más seguros, más baratos y menos toxicos que los que hoy se recetan (The Lancet, 1994, p. 1515). El autor señala asimismo la posible importancia de la investigación de "nutricéuticos" (plantas alimenticias utilizadas como medicina preventiva, es decir, antioxidantes) (lbid.), aunque también reconoce que es difícil conseguir financiación para estas actividades.

La probabilidad de introducir un nuevo fármaco en ei mercado gracias a la bioprospección oscila entre

biotecnología (biomédica, agrícola $e$ industrial) en particular. Véase un andisis del desarrollo de la biotecnología en Cuba en Feinsilver, 1993 (capitulo 5 sobre biotecnologia), y en Peinsilver, 1994, pp. 167-189. 
1 en 80000 y 1 en 250000 . Con posibilidades de éxito tan ínfimas, cabrfa preguntarse por qué vale la pena intentarlo. En primer lugar se pueden obtener beneficios educativos importantes al concentrarse en una serie de disciplinas científicas relacionadas no sólo con el medio ambiente, sino también con la ingenierfa genética y la informática; entre ellos, la formación de una fuerza de trabajo capacitada para encarar los problemas científicos actuales y los del próximo siglo. En segundo lugar, hay repercusiones positivas en otras áreas economicas, como una educación científica mejor orientada y la creación de capacidades en la esfera de la ciencia y la tecnología. Como se sabe, los logros científicos en un ámbito muchas veces se utilizan en otros ya sea directamente o adaptándolos. En el desarrollo de la biotecnología las técnicas están normalizadas, y sus aplicaciones varían enornemente, desde la investigación médica humana hasta el uso agrícola e industrial. Con esto no se quiere decir que la capacitación en una de estas áreas habilita para trabajar en otra, sino que muchas técnicas son comunes a todas.

Para que las políticas de bioprospección logren su cometido, es mejor que formen parte de un plan más amplio, tanto de desarrollo economico como de preservación ambiental (desarrollo sustentable). Es fundamental la coordinación de instituciones que podrían participar en los distintos aspectos de los programas, creados a fin de evitar la duplicación de esfuerzos y el uso ineficiente, y posiblemente ineficaz, de los recursos. Para formular la política pública, y para vigilar la aplicación de programas que vinculen a los distintos actores en una red de arreglos institucionales de colaboración que se fortalezcan mutuamente, se hace necesario un apoyo gubernamental de alto nivel.

A fin de cumplir con las obligaciones del Convenio sobre la Diversidad Biológica, los paises deberán hacer un inventario de su biodiversidad, que luego serviría de base no sólo para los esfuerzos de preservación, sino también para el desarrollo sustentable, y posiblemente para las actividades de bioprospección. Aun sin el inventario, los países e instituciones pueden seguir ofreciendo sus servicios como entidades de recolección; las empresas farmacéuticas no necesitan tener información de todo lo que existe en el país para hacer pruebas en gran escala, pero sí una buena y exacta identificación de las muestras.

Las instituciones y países podrían establecer como mínimo su capacidad de recolección y extracción en un alto nivel de confiabilidad y calidad. Deben velar por que las muestras y extractos suministrados puedan volver a recogerse sin dificultad, $y$ en mayores canti- dades, si fuera necesario; por su correcta descripción y catalogacion, asi como por el ingreso de estos datos en archivos computacionales, y por su envío sin riesgo de contaminación. La tecnología necesaria no es de gran complejidad, pero sí requiere personal capacitado y sumamente cuidadoso. Además, en lo posible, debería estudiarse y registrarse el conocimiento etnobotánico existente. Por simples que parezcan, estas etapas tienen cierto grado de dificultad.

A partir del madelo del INBio, se podrían formar y supervisar parataxónomos, recurriendo a biólogos y taxónomos capacitados. La supervisión permanente es esencial. La identificación, descripción e ingreso de los datos puede hacerse en cualquier sitio, contando sólo con un computador portátil, un codificador de barras y un escáner. El secado y envasado de las muestras puede realizarse con un mínimo de infraestructura. $\mathrm{La}$ extracción, en cambio, requiere un laboratorio, electricidad estable y adecuados servicios de almacenamiento. Uno o varios departamentos de química de las universidades de la zona podrían crear laboratorios de extracción, de preferencia para uso de un consorcio de recolectores, bajo la supervisión de un programa departamental o interdepartamental, o bien a cargo de una institución de investigación externa, de una organización no gubernamental o del sector privado. Seguramente será preciso subsidiar los gastos de puesta en marcha; previo un análisis de mercado, quizá se podría encontrar alguna empresa dispuesta a negociar un acuerdo de canje de suministros por equipos para las etapas iniciales del contrato.

Si fuera posible, los países o instituciones también podrían crear servicios de fraccionamiento, aislacion, caracterización y determinación de estructura sobre la base de ensayos biológicos, así como servicios de diagnóstico. Los pafses con suficiente capacidad científica también podrían intentar sintetizar compuestos activos, ya que en general los agentes derivados de productos naturales, una vez purificados de sus caldos, no dan origen a buenos fármacos. Pueden presentar problemas de formulación, de biodisponibilidad, de estabilidad inadecuada, o bien efectos laterales tóxicos como agentes únicos. En muchos casos los programas análogos se elaboran para superar estos problemas, más que para evadit una patente determinada. ${ }^{40}$

Por cierto, el desarrollo o perfeccionamiento de la capacidad científica mencionada es mucho más

\footnotetext{
40 Comentario de James McChesney en el debate posterior a la presentación de Cragg y otros, en el Simposio $\mathrm{N}^{*} 185$ de la Fundaeibn cro (Cragg y otros, 1994a, p. 194).
} 
oneroso, tanto en términos de equipamiento como de nivel de capacitación. Sin embargo, no está fuera del alcance de muchos países en desarrollo y podría emprenderse a escala regional, en consorcios federales o multinacionales de investigación para el desarro1lo. Los países podrían procurar acceder a la capacitación especializada en materia de elaboración y uso de pruebas de deteccion que es impartida a ciertos extranjeros por la División de Productos Naturales del Instituto Nacionai del Cáncer de los Estados Unidos y por universidades conexas. Los organismos estatales de fínanciación podrían dar prioridad a los estudios de posgrado en estas disciplinas y las universidades podrían elaborar programas interdisciplinarios para capacitar científicos en distintos niveles del ámbito de la química y la biología molecular, y para perfeccionar la capacitación en ingeniería genética. En definitiva, el objetivo sería diseñar pruebas teniendo a la vista enfermedades propias del país, que probablemente no sean motivo de mayor preocupación para las empresas farmacéuticas transnacionales, y aplicar las pruebas existentes, que pueden adquirirse en el Instituto Nacional del Cáncer, para examinar muestras de la biodiversidad local con vistas al tratamiento contra el cáncer y el SIDA.

La idea de crear una industria farmacéutica en el país puede no ser eficiente en función de los costos, pero quizá tenga sentido por razones ajenas a la economía. Si ya existe una industria farmacéutica o una capacidad nacional en materia de química fina y biología molecular, valdría la pena hacer todos los esfuerzos posibles por elaborar o adquirir pruebas para hacer ensayos de la biodiversidad del país en busca de compuestos potencialmente activos. Lo difícil es llegar a un compuesto útil, fácilmente aplicable, más eficaz que los remedios existentes, que cumpla las normas sobre toxicidad, cuya producción no sea ni complicada ni cara, y que no esté ya patentado (aunque en el tercer mundo este problema no es frecuente). Junto con buscar compuestos activos para medicinas alopáticas, los países también podrían abordar sus propios problemas de salud en el mercado nacional de servicios de atención primaria, con el fín de elaborar fármacos derivados de la biodiversidad y basados en prácticas médicas tradicionales aunque científicamente fundamentadas. Estos medicamentos deberfan someterse a una acuciosa evaluación, y debería normalizarse su dosificación, controlarse atentamente su calidad y vigilarse su distribución (The Lancet, 1994, pp. 15131515).
Los paises que carezcan de una infraestructura científica suficiente para el diseño de pruebas y el fraccionamiento y determinación de estructuras químicas mediante ensayos biologicos podrían investigar técnicas de producción agrícola que permitan maximizar el rendimiento de algunas plantas de importancia económica. Si tienen cierta especialización en biotecnología agrícola, podrían estudiar la forma de maximizar la producción del compuesto activo de la planta; la importancia de esto radica en que las drogas derivadas de productos naturales surelen ser moléculas muy complejas con muchos centros quirales y, como tales, plantean enormes dificultades para su producción sintêtica. Hay drogas anticancerosas derivadas de plantas, como la vinblastina y la vincristina, que aún se siguen aislando de la planta original, Catharanthus roseus, por más que se ha intentado producirlas sintéticamente durante más de 20 años. Asimismo, las drogas anticancerosas derivadas de microbios, como la bleomicina y la daunorubicina, aún se producen por fermentacion, y no totalmente en forma sintética (Cragg, 1993b).

En suma, las primeras conclusiones indican que la prospección de la biodiversidad en busca de nuevos fármacos no es una panacea para el desarrollo, pero que podría, en el largo plazo, acarrear beneficios, siempre que los países en desarrollo cuenten con condiciones adecuadas en cuanto a infraestructura científica, leyes de propiedad intelectual, áreas de conservación y capacidad de negociación; $y$, asimismo tengan voluntad política para colaborar entre sf y con las industrias de los países desarrollados. Sin embargo, el mercado de aceites esenciales (sobre todo para la fabricación de cosméticos), fitofármacos y preparados de hierbas es más amplio y accesible que el de compuestos nuevos potencialmente utilizables en la industria farmacéutica. El largo período de prueba a que se someten los fármacos torna improbable el beneficio inmediato; sus posibilidades están en el largo plazo. Cabe señalar Ios importantes efectos secundarios que se producen en otros sectores, en especial la agricultura y la industria, por cuanto se desarrolla capacidad cientffica para agregar valor en las distintas etapas del proceso de prospección de la biodiversidad y de elaboración de fármacos. Estos efectos hacen más racional invertir en estas actividades, a pesar de la limitación del beneficio económico inmediato.

(Traducido del inglés) 
Bibliografía

AIDS Weekly (1995): Atlanta, Georgia, (ed. e imp.) Charles W. Henderson, 6 de noviembre.

Alyward, B.A.. J. Echeverría, L. Fendt y E.B. Barbier (1993): The economic value of species information and its role in biodiversity conservation, London Environmental Economics Centre Discussion Paper, $\mathrm{N}^{*}$ 6, Londres, Environmental Economics Centre. Diciembre.

Asebey, E. (1996): Andes Pharmacenticals, Inc.: un nuevo modelo para la prospección de la diversidad biologica, en J.M. Feinsilver (ed.), Biodiversidad, biotecnologia y desarrollo sostenible en salud y agriculitura: contexiones emergentes, Publicación científica, $\mathbf{N}^{\circ} 560$, Washington, D.C., Organización Panamericana de In Salud (OPS)/Organización Mundial de la Salud (OMs).

Biotechnology Newswatch (1995): Nueva York, Mc Graw-Hill Publishers, 19 de junio.

Bioventure View (1995a); vol. 9, No 7, San Mateo, Califomia, BioVenture Publishing, 9 de agosto

(1995b): San Mateo, California, BioVenture Publishing. 1 de noviembre.

Burrill, G. S. y K. B. Lee, Jx. (1993): Biotech 94: Long-Term Value. Short-Term Hurdles, Sin Francisco, California, Ernst \& Young, Ine.

Caporale, L. H. y M. F. Dermody (1996): El descubrimuento de medicamentos y la diversidad biológica: colaboraciones y riesgos en el descubrimiento de nuevos productos, en J.M. Feinsilver (ed.), Biodiversidad, biotecnologta y desarrollo sostenible en salud y agricultura: conexiones emergentes, Publicación científica, $\mathrm{N}^{\circ} \mathbf{5 6 0}$, Washington, D.C., OPS/OMS.

Chapela, I.H. (1996): La bioprospección en la era de la información: un análisis critico de las iniciativas de conservación asociadas con el descubrimiento de nuevos fármacos, en J.M. Feinsilver (ed.), Biodiver,idad, biotecnologia y desarrollo sostenible en salud y agricultura: conexiones emergentes, Publicación científica, $\mathrm{N}^{\circ} 560$, Washington. D.C., ops/oms.

Cragg, G.M. y otros (1993a): Role of plants in the National Institute Drug Discovery and Developtnent Program, en A.D. Kinghom y M.F. Balandrin (eds.), Human Medicinal Agents form Plants, Washington, D.C., American Chernical Society.

(1993b): The search for new pharmaceutical crops: drug discovery and development at the National Cancer Institute, en J. Janick y J. E. Simon (eds.) New Crops, Nueva York, John Wiley and Sons, Inc.

(1994a): Ethnobotany and drug discovery: The experience of the US National Cancer Institute, en Ethmobotany and the Search for New Drags, Wiley, Reino Unido, Simposio $\mathrm{N}^{0} 185$ de la Fundación Ciba.

(1994b): Drug discovery and development at the United States National Cancer Institute. International collaboration in the search for new drugs from natural sources, Eighth Asiars Symposium on Medicinal Plants and Species and Other Natural Products, Melaca, Malasia, 13 al 16 de junio (por publicarse en Proceeding, of the Eighth Astan Symposium on Medicinal Plants and Species and Other Natural Products).

Feinsitver, J.M. (1993); Healing the Masses: Cuban Health Politics at Home and Abroad, Berkeley, California, University of Califomia Press.

(1994): Cuban biotechnology: A first world approach to development, en J.F. Pérez-Lopez (ed.), Cuba at a Crossroads: Politics and Economics, Gainesville, Florida, University of Florida Press.

ed. (1996): Biodiversidad, biotecnología y desarrollo sostenible en salud y agriculoura: conexiones emergentes, Publjcación científica, $\mathrm{N}^{\mathrm{D}} 560$, Washington D.C, OPS/OMS.
Feinsilver, J.M. e I.H. Chapela (1996): Comentario: ¿llevará la prospección de la diversidad biológica para obtener fármacos al descubrimiento del "oro verde"? en J.M. Feinsilver (ed.), Biodiversidad, biotecnología y desarrollo sostenible en salud y agricultura: conexiones emergentes, Publicación científica, No 560, Washington, D.C., OPS/OMS.

Grifo, F.T. (1996): Prospección quImica: una visión general del Programa Internacional de Grupos de Cooperación sobre Biodiversidad, en J.M. Feinsilver (ed.), Biodiversidad, biotecnologia y desarrollo sostenible en salud y agricultura: conexiones emergentes, Publicación científica, $\mathrm{N}^{\circ} 560$, Washington, D.C., OP3/OMs.

INBio (Instituto Nacional de Biodiversidad ( (1992): Informe anual de labores, 1991, Heredia, Costa Rica, INBio.

Juma, C. (1993): Policy options for scientific and technological capacity-building, en W.V. Reid y otros, Biodiversity Prospecting: Using. Genetic Resources for Sustainable Development, Washington, D.C., Instituto Mundial de Recursos.

Pharmaceutical Business News (1995): Londres, 8 de noviembre.

Raven, P. (1994): ¿Por qué es importante la biodiversidad?, en Nuestro Planefa, vol. 6, No 4, Nairobi, Kenya, Programa de las Naciones Unidas para el Medio Ambiente (PNUMA).

Rosenthal, J. (por publicarse): The International Cooperative Biodiversity Groups Program: Lessons from the first two years, en F. Grifo y J. Rosenthal (eds.), Biodiversity and Human Health, Washington, D.C., Island Press, mimeo.

Schweitzer, J. y otros (1991); Summary of the workshop on drug development, biological diversity and economic growth, Journal of the National Cancer Institute, vol. 83, $\mathrm{N}^{\circ} 18$, Bethesda, Maryiand, National Cancer Institute (NCI), septiernbre.

Sittenfeld, A. (1993): INBio's biodiversity prospecting framework, en W.V. Reid y otros, Biodiversity Prospecting: Using Genetic Resources for Sustainable Development, Washington, D.C.. Instituto Mundial de Recursos.

(1994): Biodiversity prospecting frameworks: The INBio's experience in Costa Rica, trabajo presentado a la Conferencia Internacional Biolegical Diversity: Exploring the Complexities, Tucson, Arizona, Universidad de Arizona, 25 al 27 de marzo.

Ten Kate, K. (1995): Biopiracy or Green Petroleum?' Expecsution \& Best Practice in Bioprospecting, Londres. Dirección de Desarrollo de Ultramar (ODA), Departamento de política ambiental, octubre.

The Bemstein Report on BioBusiness (1994): Shaman inverts its drug development model, BioCentury Part II., 14 de noviembre.

The Lancet (1994): Pharmaceulicals form plants: great potentjal, fow funds, vol. 8912, $\mathrm{N}^{\circ} 343$, Londres, 18 de junio.

The New York Times (1994): New version of taxol is approved by F.D.A., Nueva York, 13 de diciembre.

The Wall Street Journal (1994): Nueva York, 13 de octubre. (1995): Nueva York, 26 de octubre.

USAID (Agencia de los Estados Unidos para el Desartollo Internacional)/NIH (National Institute of Health)/NSF (National Science Foundation) (1993): First Five-Year-Awards aje announced under Interagency Biodjversity Program, Washington, D.C., 7 de diciembre, comunicado de prensa.

Zisson, A. (1993): Shaman Pharmaceuticals, Inc. Contpany Report, San Francisco, California, Hambrecht \& Quist Inc. (Stock Brokers), 22 de diciembre. 